\title{
Tribocorrosion behavior of nickel-aluminium bronze sliding against alumina under the lubrication by seawater with different halide concentrations
}

\author{
Beibei ZHANG ${ }^{1,2}$, Jianzhang WANG ${ }^{1, *}$, Junya YUAN ${ }^{1,2}$, Fengyuan YAN $^{1,{ }^{*}}$ \\ ${ }^{I}$ State Key Laboratory of Solid Lubrication, Lanzhou Institute of Chemical Physics, Chinese Academy of Sciences, Lanzhou 730000, China \\ ${ }^{2}$ University of Chinese Academy of Sciences, Beijing 100049, China \\ Received: 12 October 2017 / Revised: 12 January 2018/Accepted: 24 April 2018 \\ (C) The author(s) 2018. This article is published with open access at Springerlink.com
}

\begin{abstract}
The tribocorrosion failure mechanism of nickel-aluminium bronze (NAB) in different halide concentrations of seawater was studied using a pin-on-disc tribometer that was modified to conduct in-situ electrochemical detection during the sliding process. It has been reported that high-halide-concentration seawater provided a good lubricating effect, and thus reduced the coefficient of friction and wear rate of NAB during the tribocorrosion process. However, the existence of halide ions corroded the passive film and hindered the repassivation of the damaged areas in the wear track, resulting in an increased corrosion rate. In addition, the morphology of the wear scar revealed the occurrence of abrasive, delamination, and adhesive wear of NAB in seawater. For the whole range of halide concentration values, a positive synergy between wear and corrosion was proven, and the quantification of this synergy was discussed in detail. The results show that the corrosionwear synergism was decreased with increasing halide concentration in seawater, and the corrosion-induced wear was dominant in the two synergistic components.
\end{abstract}

Keywords: tribocorrosion; halide ions; friction; wear

\section{Introduction}

Corrosion is a major cause of failure in marine engineering parts, and has resulted in significant economic losses. For the majority of engineering components, this phenomenon is inevitable owing to the presence of aggressive species in seawater, in particular halide ions [1, 2]. Usually, besides suffering from corrosion attacks, many key components of marine systems are exposed to wear in diverse forms, such as sliding, rolling, impacting, or fretting. The term tribocorrosion is defined to describe this kind of material degradation, which is a result of the combined corrosion and tribological process [3]. From this perspective, it is not sufficient to predict the tribocorrosion behavior of metals with a knowledge of only electrochemical behavior without any mechanical wear, or with the knowledge of frictional wear behavior in the absence of corrosive environments. Tribocorrosion involves chemical, mechanical, and electrochemical mechanisms and the combination of these mechanisms often leads to synergistic effects between wear and corrosion. During the course of tribocorrosion, frictional motion can modify the sensitivity of metal surfaces to corrosion. However, corrosion impacts the wear resistance by changing the abrasive condition between the two moving contact surfaces. Thus, the total mass-loss rate of metallic materials in tribocorrosion systems clearly exceeds the sum of the wear rate and corrosion rate, which are measured individually [4-6]. It is therefore necessary to obtain more information on the tribocorrosion

* Corresponding authors: Jianzhang WANG, E-mail: wjzsci@163.com; Fengyuan YAN, E-mail: fyyan@licp.cas.cn 
behavior of metallic materials in aggressive media, especially before they are considered as alternative materials for practical applications.

NAB alloys possess good mechanical properties and superior corrosion resistance, so for several decades, they have been applied in a wide variety of saline or marine environments, serving as pump shafts, valve stems, fittings, and ship propellers, among other functions [7]. The excellent corrosion resistance of $\mathrm{NAB}$ depends on the formation of a protective film or layer of corrosion products, which is mainly composed of copper and aluminium oxide/hydroxide. In particular, the aluminium element in NAB alloys enables them to rapidly generate the aluminium-rich protective film, leading to an insensitivity to localized breakdown and pitting corrosion in the presence of halide ions. At the same time, the addition of nickel and iron also improves its corrosion resistance as well as mechanical properties, such as the tensile and yield strength $[8,9]$. However, during the service life of NAB alloys, they are often subjected to abrasion, erosion, scratching, or other forms of wear damage in aggressive media, particularly in seawater [10]. This can lead to a deterioration or even complete removal of the passive oxide film, resulting in the exposure of a fresh metal surface to corrosive media and following the increased corrosion rate. In turn, the accelerated wear rate can be induced by the increasing corrosion rate. Hence, under both of the electrochemical and mechanical solicitations, the synergistic effects of corrosion and wear lead to accelerated material removal, which have high potential risk if there is a failure of the running devices.

It is well known that the tribocorrosion behavior largely depends on the environmental properties, the metallographic structure, and chemical composition of contacting materials as well as the mechanics of the tribological contact [11]. The most common influencing factor for copper alloys may be in actual service environments (i.e., seawater), which has a concentration of aggressive ions, notably chloride ions. Although the vast majority of seawater has a salinity ranging between $3.1 \%$ and $3.8 \%$, seawater is not uniformly saline worldwide. Variations in the salinity of seawater are influenced primarily by changes in the water content of the seawater. Where mixing occurs with fresh water runoff from river mouths, near melting glaciers or vast amounts of precipitation, seawater may be markedly less saline. Alternatively, the salinity in isolated bodies of water can be considerably greater, which is about ten times higher in the case of the Dead Sea [12]. In this case, the function of the salinity in tribocorrosion systems has attracted much attention by a number of tribologists and corrosion researchers. As observed by Badawy et al. [13], the corrosion rate of $\mathrm{Cu}-\mathrm{Ni}$ alloys increases with an increase of the chloride concentration up to $0.3 \mathrm{~mol} \cdot \mathrm{dm}^{-3}$, and then decreases at higher concentration. However, according to the results from Ismail et al. [14], the dissolution rate of $\mathrm{Cu}-38 \mathrm{Zn}$ in borate solutions decreases with the increase in the $\mathrm{Cl}^{-}$ion concentration (0.01 M-0.2 M) owing to the formation of insoluble $\mathrm{CuCl}$. For $\mathrm{Cl}^{-}$ion concentration $>0.2 \mathrm{M}$, the corrosion rate increases as the soluble $\mathrm{CuCl}_{2}{ }^{-}$complex are produced. Although many kinds of copper alloy have been studied, there have been few studies about the tribocorrosion behavior of NAB in seawater with different halide-ion concentrations. Therefore, in the present work, we performed systematic study to reveal the effect of halide-ion concentrations on the tribocorrosion behavior of NAB in seawater. From a practical point of view, this study is important to gaining a deep understanding of optimized environmental parameters selection to control the corrosive wear of NAB alloys in their service time.

\section{Experimental procedure}

The material used in this work is cast NAB UNS C95800 (without heat treatment), with the major chemical compositions (in wt.\%) as follows: $9.17 \% \mathrm{Al}$, $4.17 \% \mathrm{Fe}, 4.4 \% \mathrm{Ni}, 1.28 \% \mathrm{Mn}$ and balance $\mathrm{Cu}$. For tribocorrosion tests, the samples were cut into a ring form with an outer diameter of $54 \mathrm{~mm}$ and an inner diameter of $38 \mathrm{~mm}$. Test surfaces of samples were wet ground using a series of $\mathrm{SiC}$ papers down to the 1,500 grade, followed by cleaning with distilled water and ultrasonically degreasing with acetone. The resulting roughness of the used sample was $0.04 \mu \mathrm{m}$, as measured by a 2206 surface roughness tester (Links, China). To obtain a mirror-like surface, the samples were mechanically polished using diamond paste. Before being put into the tribo-electrochemical cell, all other surfaces, with the exception of the test surface 
of specimens, were masked by a layer of insulating paint. The test solution is artificial seawater with a $\mathrm{pH}$ of 8.2, and is prepared from deionized water and analytical grade reagents according to ASTM D114198. Because the composition of natural seawater varies with sea area, depth, and season, the artificial seawater is used to improve the reproducibility of the test. In artificial seawater, halide ions include mainly chloride ions $\left(\mathrm{Cl}^{-}\right)$, bromide ions $\left(\mathrm{Br}^{-}\right)$, and fluorine ions $\left(\mathrm{F}^{-}\right)$, and there remain other anions, such as bicarbonate ion and sulfate ion. The concentration of halide ions (denoted as [C]) in the electrolyte used in this work was adjusted to $0 \mathrm{M}, 0.2 \mathrm{M}, 0.5 \mathrm{M}, 0.8 \mathrm{M}$, and $1.0 \mathrm{M}$, with the concentration of $\mathrm{Br}^{-}$(denoted as $\left[\mathrm{Br}^{-}\right]$) and $\mathrm{F}^{-}$ (denoted as [F-]) being constant. That is, the variation of [C] was achieved by controlling the addition of $\mathrm{NaCl}$ in the experiment. The concentrations of the main compounds in the electrolyte are presented in Table 1.

Tribocorrosion testing was carried out in an MMW-1 sliding pin-on-disc tribometer integrated with an electrochemical workstation and its schematic diagram was the same as described in Ref. [15]. During the test, an inert $\mathrm{Al}_{2} \mathrm{O}_{3}$ cylinder (with a diameter of $4 \mathrm{~mm}$ ) slid against the stationary specimen inserted into the test cell with the $400 \mathrm{~mL}$ electrolyte, under a controlled normal load of $125 \mathrm{~N}$ and sliding speed of $100 \mathrm{rpm}$. The friction coefficient was measured continuously by an attached strain gauge, and was recorded using a computer acquisition system. To achieve electrical insulation from the surrounding environment, the test cell and the specimen holder were both made of Teflon, which was an insulating and corrosion-resistant material. The tribo-electrochemical cell consisted of a NAB alloy sample as a working electrode, an $\mathrm{Ag} / \mathrm{AgCl}$ reference electrode, and a platinum gauze as the auxiliary electrode. All of the experiments were performed at room temperature $\left(22^{\circ} \mathrm{C}\right)$, and repeated at least three times in order to ensure reproducibility.

During tribocorrosion testing, the corrosion performance of NAB alloy in different solutions was estimated by measuring the open-circuit potential (OCP) and potentiodynamic polarization curves. OCP measurements were conducted in the absence of sliding for a time period of $1,200 \mathrm{~s}$, and subsequently with sliding for $3,600 \mathrm{~s}$. Then, it was continuously monitored for $1,200 \mathrm{~s}$ when sliding was stopped. Potentiodynamic polarization measurements were performed under two conditions: without sliding (static corrosion) and in the presence of sliding (tribocorrosion). Under both conditions, the polarization scans were initiated from $-0.8 \mathrm{~V}$ to $+0.6 \mathrm{~V}$ at a sweep rate of $2 \mathrm{mV} \cdot \mathrm{s}^{-1}$. Before each potentiodynamic polarization measurement, the sample was allowed to stabilize for 1,200 s. In order to clarify the role of the wear on the total material loss, a cathodic potential of $-0.8 \mathrm{~V}$ was applied to specimens under respective conditions.

The morphologies of the wear debris, worn surfaces, and subsurfaces of tested specimens were examined by a JEM-5600LV scanning electron microscope (SEM). Prior to characterizing the subsurfaces, the cross section was etched with a solution, including $5 \mathrm{~g}$ $\mathrm{FeCl}_{3}, 2 \mathrm{~mL} \mathrm{HCl}$ and $95 \mathrm{~mL} \mathrm{C} \mathrm{H}_{5} \mathrm{OH}$. The chemical composition of the alumina counterface was examined using an energy-dispersive spectrometer (EDS). The phase compositions of the NAB alloy were characterized by a PANalytical Empyrean X-ray diffraction (XRD) with $\mathrm{Cu} \mathrm{K} \alpha$ radiation.

Table 1 Concentration of the main compound in seawater.

\begin{tabular}{cccccccccccc}
\hline & \multicolumn{10}{c}{ Compound concentration / M } \\
\cline { 2 - 10 } & $\mathrm{NaCl}$ & $\mathrm{MgCl}_{2}$ & $\mathrm{CaCl}_{2}$ & $\mathrm{KCl}$ & $\mathrm{SrCl}_{2} \cdot 6 \mathrm{H}_{2} \mathrm{O}$ & $\mathrm{KBr}$ & $\mathrm{NaF}$ & $\mathrm{Na}_{2} \mathrm{SO}_{4}$ & $\mathrm{NaHCO}_{3}$ & $\mathrm{H}_{3} \mathrm{BO}_{3}$ \\
\hline 0 & 0 & 0 & 0 & 0 & 0 & 0 & 0 & 0.029 & 0.002 & $0.437 \times 10^{-3}$ \\
0.2 & 0.061 & 0.055 & 0.010 & 0.009 & $0.158 \times 10^{-3}$ & $0.779 \times 10^{-3}$ & $0.071 \times 10^{-3}$ & 0.029 & 0.002 & $0.437 \times 10^{-3}$ \\
0.5 & 0.361 & 0.055 & 0.010 & 0.009 & $0.158 \times 10^{-3}$ & $0.779 \times 10^{-3}$ & $0.071 \times 10^{-3}$ & 0.029 & 0.002 & $0.437 \times 10^{-3}$ \\
0.8 & 0.661 & 0.055 & 0.010 & 0.009 & $0.158 \times 10^{-3}$ & $0.779 \times 10^{-3}$ & $0.071 \times 10^{-3}$ & 0.029 & 0.002 & $0.437 \times 10^{-3}$ \\
1.0 & 0.861 & 0.055 & 0.010 & 0.009 & $0.158 \times 10^{-3}$ & $0.779 \times 10^{-3}$ & $0.071 \times 10^{-3}$ & 0.029 & 0.002 & $0.437 \times 10^{-3}$ \\
\hline
\end{tabular}




\section{Results and discussion}

\subsection{Microstructure characterization}

The SEM micrograph and the XRD pattern of the NAB alloy used in this test are shown in Fig. 1. The microstructure of the NAB alloy was mainly composed of an $\alpha$ phase, a $\beta^{\prime}$ phase, and several intermetallic $\kappa$ phases, as labeled in Fig. 1(a). The $\alpha$ phase as the matrix was a copper-rich solid solution, and the $\beta^{\prime}$ phase was a solid solution with a martensitic structure. For the NAB used in this experiment, there were three types of $\kappa$ phases (designated $\kappa_{\mathrm{II}}, \kappa_{\mathrm{II}}$, and $\kappa_{\mathrm{IV}}$ ), which were distinguished by their different shapes, sizes and distribution. The $\kappa_{\text {II }}$ showed a dendritic (rosette-like) shape and was mainly distributed at the

(a)
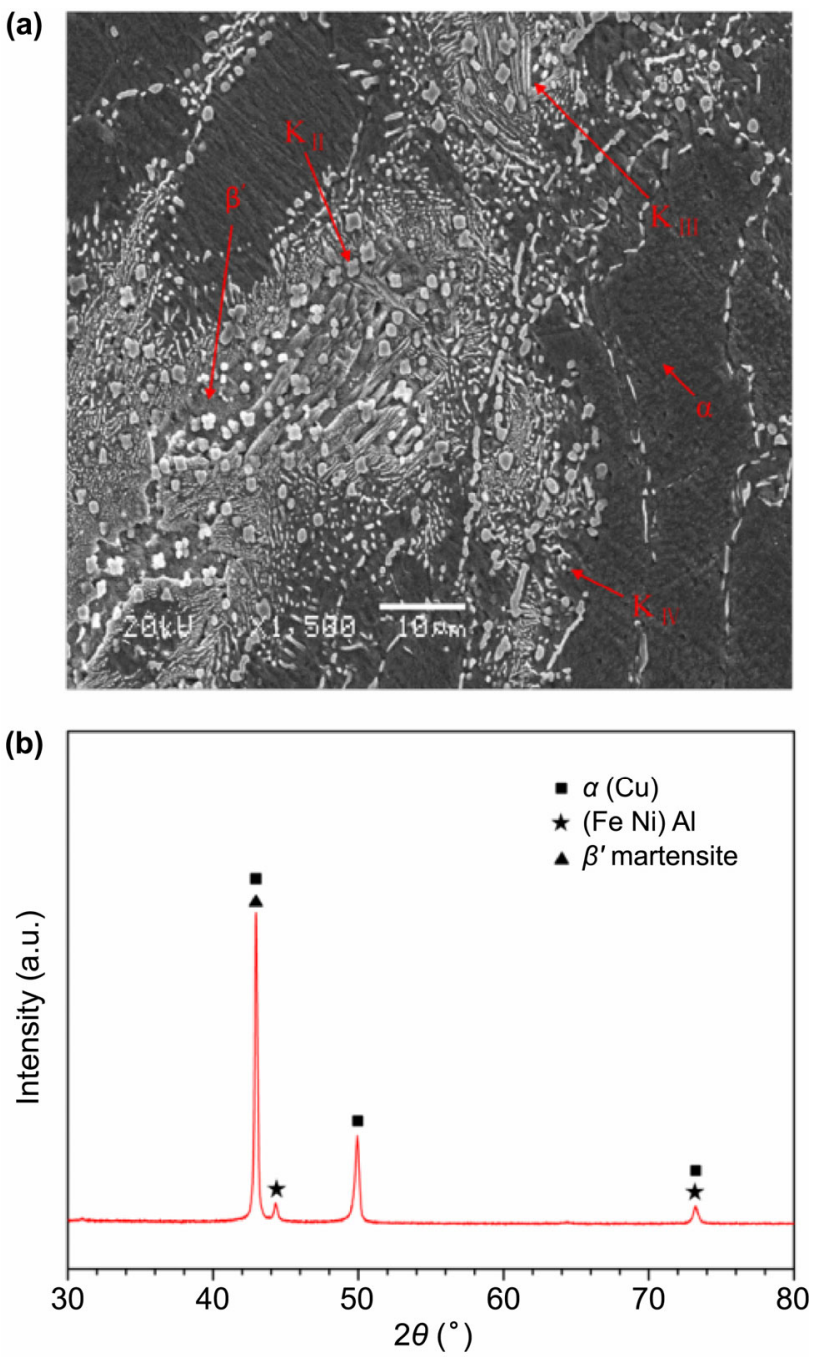

Fig. 1 SEM microstructure (a) and XRD pattern (b) of NAB alloy. boundaries of the $\alpha$ and $\beta$ phases. The $\kappa_{\mathrm{III}}$ exhibited a laminar eutectoid structure, and was generally found to be perpendicular to the $\alpha$ and $\beta$ boundaries. For the $\kappa_{\mathrm{IV}}$ phase, it appeared as a fine particle morphology, and was typically embedded in $\alpha$ matrix $[16,17]$.

The phase constituents of NAB alloy were analyzed using XRD, and the results are presented in Fig. 1(b). It can be seen that the diffraction peaks of the $\alpha$ phase, $\beta^{\prime}$ martensite phase, and another phase, including aluminium-iron-nickel intermetallics, appeared in the tested NAB alloy, which was consistent with the SEM observation results. From the previously reported literature, it is well known that the $\kappa_{\mathrm{I}}, \kappa_{\mathrm{II}}$, and $\kappa_{\mathrm{IV}}$ phases were iron-enriched precipitates on the structure of $\mathrm{Fe}_{3} \mathrm{Al}$, while the $\kappa_{\text {III }}$ phase was nickel-enriched based on NiAl [18]. Thus, combined with the microstructural image in Fig. 1(a), the diffraction peaks of intermetallics were attributed to the presence of the $\kappa_{\mathrm{II}}, \kappa_{\mathrm{III}}$, and $\kappa_{\mathrm{IV}}$ phases in NAB alloy.

\subsection{Electrochemical behavior of NAB}

In situ information of the surface state of NAB under combined wear and corrosion impact was obtained by performing OCP measurements. For the investigated $\mathrm{NAB}$ in the seawater containing different halide-ion concentrations, the results of the OCP are shown in Fig. 2. Before sliding, the OCP was allowed to stabilize for 1,200 s. During this period, the steady-state potential was reached, indicating the presence of passive film on the sample surface. At the beginning of the friction,

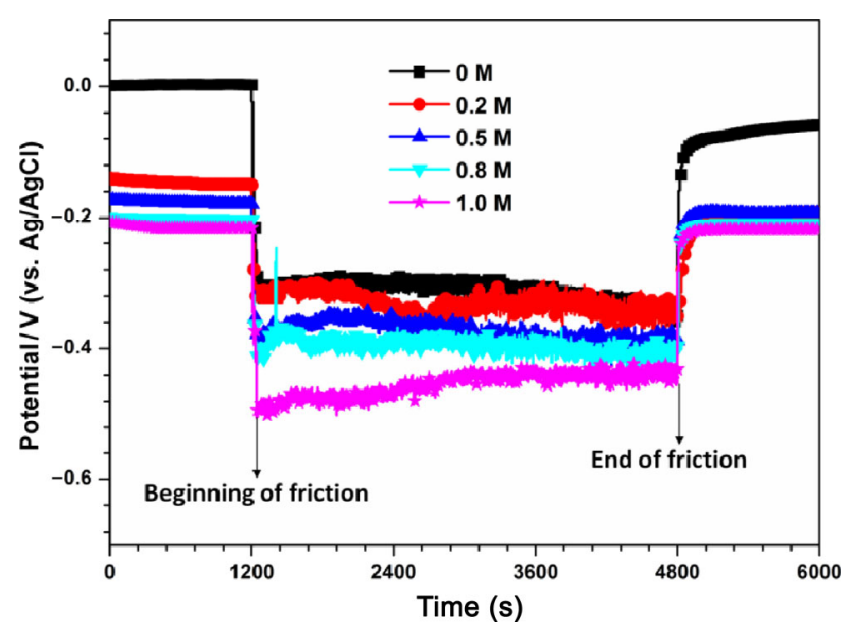

Fig. 2 OCP curves of NAB alloy in artificial seawater with different halide-ion concentrations. 
the OCP decreased abruptly and then fluctuated about a certain value during the sliding period. It is common knowledge that the OCP that was recorded during tribocorrosion tests is a mixed potential reflecting the state of worn and unworn surfaces [19]. The OCP depends on the ratio and relative position of worn and unworn areas, as well as the respective intrinsic OCP of the materials in worn and unworn areas. Thus, the cathodic shift of the OCP owing to sliding can be attributed to the removal of passive oxide film on the sample surface, leading to a destruction of the passive state and the activation of metal inside the wear track. Afterwards, there was a galvanic couple between worn and unworn surfaces of material. In a galvanic cell, the anodic current $I_{\mathrm{a}}$ is equal to the absolute cathodic current $I_{\mathrm{c}^{*}}$. Considering the anodic current density $\left(i_{\mathrm{a}}\right)$ and cathodic current density $\left(i_{c}\right)$, one equation can be written for the case of tribocorrosion tests [20]:

$$
i_{\mathrm{a}} A_{\mathrm{a}}=-i_{\mathrm{c}} A_{\mathrm{c}}
$$

where $A_{\mathrm{a}}$ and $A_{\mathrm{c}}$ are the surface areas of the anode and cathode, respectively. The steady-state OCP during sliding was observed owing to the establishment of an equilibrium between the electrochemical passivation and mechanical depassivation rate. Once the sliding was stopped, the OCP shifted to the anodic direction, and almost returned to the initial value owing to the repassivation of the wear track. It should be noted that the fluctuation of the OCP during the sliding process can be explained by the periodic removal and re-growth of oxide film on the metal surface. Besides, during the course of sliding, the OCP decreased gradually with the increase of halide concentration in seawater, suggesting an increase in the corrosion susceptibility for NAB.

Figure 3 shows the potentiodynamic polarization curves of NAB alloy under static and sliding conditions in seawater with different halide-ion concentrations. The corresponding electrochemical parameters obtained from the polarization curves are listed in Table 2. Under the static corrosion condition (Fig. 3(a)), the corrosion potential ( $\left.E_{\text {corr }}\right)$ shifted to more negative values as the concentration of halide ions increased. The corrosion current density $\left(i_{\text {corr }}\right)$ increased with the increase in halide concentration up to $0.2 \mathrm{M}$ owing to the generation of the complex
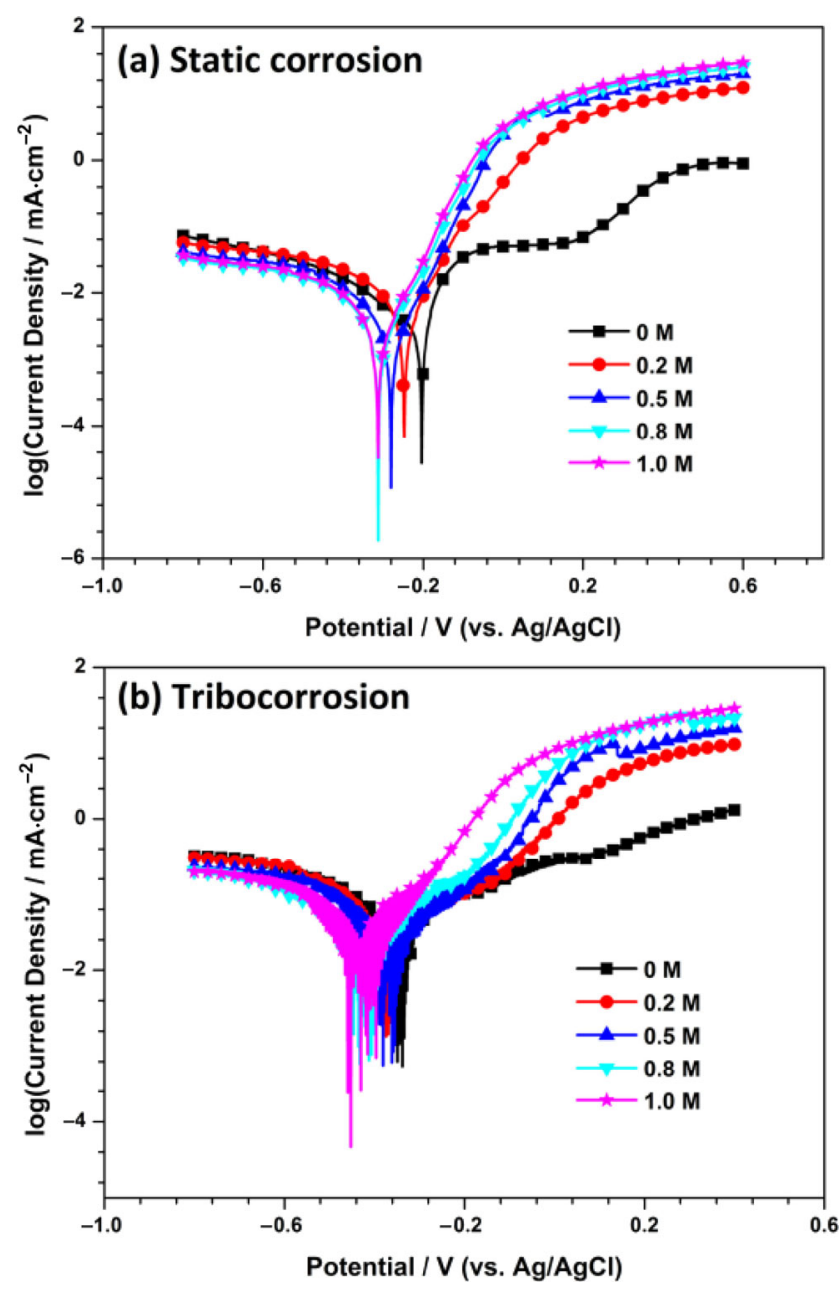

Fig. 3 Potentiodynamic polarization curves for NAB alloy under (a) static corrosion and (b) tribocorrosion conditions in seawater with different halide-ion concentrations.

$\mathrm{CuCl}_{2}{ }^{-}$. Then, a decrease in $i_{\text {corr }}$ was detected for concentrations higher than $0.2 \mathrm{M}$, which resulted from the hydrolysis of $\mathrm{CuCl}_{2}{ }^{-}$and the formation of $\mathrm{Cu}_{2} \mathrm{O}$. In this testing system, the corrosion processes of the NAB alloy were mainly the anodic dissolution of copper (Eq. (2)), and the cathodic reduction of the dissolved oxygen (Eq. (3)), as shown by the following chemical reactions [21].

$$
\begin{gathered}
\mathrm{Cu}+2 \mathrm{Cl}^{-} \rightarrow \mathrm{CuCl}_{2}^{-}+\mathrm{e}^{-} \\
\mathrm{O}_{2}+2 \mathrm{H}_{2} \mathrm{O}+4 \mathrm{e}^{-} \rightarrow 4 \mathrm{OH}^{-}
\end{gathered}
$$

In addition, cuprous oxide can be formed by the dissolution or precipitation process (Eq. (4)):

$$
2 \mathrm{CuCl}_{2}^{-}+2 \mathrm{OH}^{-} \rightarrow \mathrm{Cu}_{2} \mathrm{O}+\mathrm{H}_{2} \mathrm{O}+4 \mathrm{Cl}^{-}
$$


Table 2 Corrosion parameters for NAB alloy in seawater as a function of halide ions concentration.

\begin{tabular}{|c|c|c|c|c|c|c|c|c|c|c|}
\hline \multirow{2}{*}[\mathrm{C}]{$/ \mathrm{M}$} & \multicolumn{5}{|c|}{ Static corrosion } & \multicolumn{5}{|c|}{ Tribocorrosion } \\
\hline & 0 & 0.2 & 0.5 & 0.8 & 1.0 & 0 & 0.2 & 0.5 & 0.8 & 1.0 \\
\hline$E_{\text {corr }} / \mathrm{V}_{\mathrm{Ag} / \mathrm{AgCl}}$ & -0.204 & -0.247 & -0.280 & -0.306 & -0.312 & -0.338 & -0.374 & -0.381 & -0.432 & -0.452 \\
\hline$i_{\text {corr }} / \mu \mathrm{A} \mathrm{cm}^{-2}$ & 3.74 & 4.59 & 4.03 & 2.93 & 2.73 & 23.20 & 29.52 & 35.63 & 52.86 & 64.98 \\
\hline$E_{\mathrm{pit}} / \mathrm{V}_{\mathrm{Ag} / \mathrm{AgCl}}$ & +0.178 & 一 & 一 & 一 & 一 & +0.091 & -0.110 & -0.183 & -0.242 & 一 \\
\hline
\end{tabular}

As one of the major alloying elements in NAB, aluminium can result in higher strength and better casting working properties. More importantly, the aluminium content improves the corrosion resistance of NAB owing to the formation of an oxide/hydroxide film. This layer is produced by the complexation of aluminium and chloride, followed by the hydrolysis reaction to form an aluminium hydroxide layer. The reaction equations are described as follows:

$$
\begin{gathered}
\mathrm{Al}+4 \mathrm{Cl}^{-} \rightarrow \mathrm{AlCl}_{4}^{-}+3 \mathrm{e}^{-} \\
\mathrm{AlCl}_{4}^{-}+3 \mathrm{H}_{2} \mathrm{O} \rightarrow \mathrm{Al}(\mathrm{OH})_{3}+4 \mathrm{Cl}^{-}+3 \mathrm{H}^{+}
\end{gathered}
$$

It have been reported that the oxide layer on NAB alloys is aluminium-enriched adjacent to the base metal and copper-enriched in the outer regions [22]. These layers act as a barrier and hamper the transportation of metal cations, especially the sustainable alumina protective film which can build rapidly on the alloy surface.

As shown in Fig. 3(a), when halide ions were present in the environment, no pitting corrosion was observed for the NAB alloy. Instead, in the case of the halide-free solution, the rapid increase in current density at potentials above $+0.178 \mathrm{~V}$ confirmed the occurrence of the pitting corrosion. According to the previously reported studies, attacks by pitting for copper alloys can be triggered in the presence of specific aggressive species, such as sulphate, chloride, or nitrate. Each of these species can individually produce pitting corrosion in copper alloys, but with different degrees of aggressiveness. Sulphate ions appeared to be more aggressive than chloride ions; however, when the chloride-to-sulphate content ratio exceeded 5, the species responsible for copper pitting were chloride ions, and sulphate ions did not work in this condition $[23,24]$. With respect to halide-free electrolytes, the species responsible for the pitting corrosion was sulphate ions. Considering that the ratios of chloride/sulphate were greater than 5 in halide-containing solutions, it is rational that the pitting corrosion susceptibility of NAB in halide-free seawater was the highest among all tested solutions.

Under the sliding condition (Fig. 3(b)), the potentiodynamic behavior of NAB was different from that observed under the static corrosion condition. First, the $E_{\text {corr }}$ of all specimens was shifted cathodically. Secondly, the $i_{\text {corr }}$ was increased by one order of magnitude. However, the $E_{\text {corr }}$ was shifted to an increasingly negative direction as the halide-ion concentration increased in the presence of tribological contact. Moreover, friction promoted the occurrence of pitting corrosion. The higher the halide concentration of seawater, the greater the pitting corrosion susceptibility for NAB alloys. It was generally accepted that the pitting corrosion of metals resulted from the breakdown of the passive oxide film induced by the penetration of aggressive anions (especially halide ions) under the effect of an electrostatic field across the film/solution interface [25]. The anodic overvoltage for the dissolution of metallic ions can be reduced in contact with solution containing a higher halide concentration. Thus, the increase in halide concentration would improve the possibility of absorption of halide ions on the NAB surface, which consequently reduced the pitting corrosion potentials $\left(E_{\mathrm{pit}}\right)$.

\subsection{Friction and wear behavior of NAB}

\subsubsection{Coefficient of friction and wear rate}

The coefficient of friction (COF) and mass-loss rate are important characteristics to understand the friction and wear performance on the $\mathrm{NAB} / \mathrm{Al}_{2} \mathrm{O}_{3}$ contact surface, which are dominated by the physical condition and chemical reactions between contacting interfaces as well as the environment. The evolutions 
of COF for NAB alloys with time in seawater with different halide-ion concentrations are shown in Fig. 4. It was clear that the COF decreased with the increase in halide concentration, which is owing to the good lubricity of higher halide concentration solution. The measured total mass-loss curves of NAB alloys are shown in Fig. 5. Under both of the tribocorrosion and pure mechanical wear conditions, a decreasing trend of the total mass loss of NAB with increasing halide concentration was observed. In addition, the pure mechanical wear loss was much less than the mass loss caused by tribocorrosion within the measured halide concentration range. This was attributed to the fact that, under the tribocorrosion condition, the loose corrosion product layers on the metal surface can be easily peeled off by the $\mathrm{Al}_{2} \mathrm{O}_{3}$ pin, resulting in accelerated material loss.

\subsubsection{Wear mechanism}

In order to further determine the effect of the halide concentration on the tribological behavior of $\mathrm{NAB}$
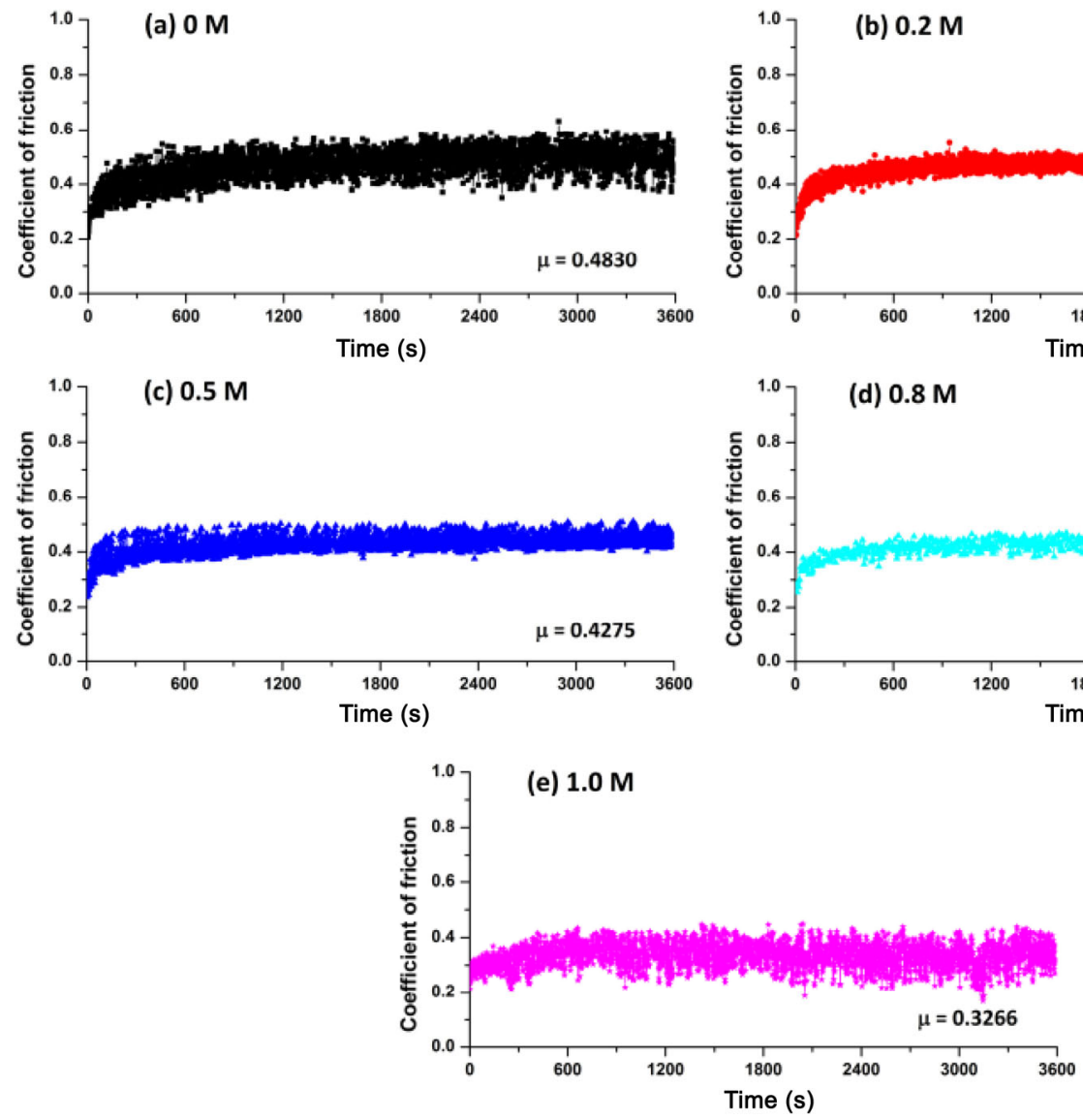

Fig. 4 Coefficient of friction for NAB alloy as a function of sliding time in seawater with different halide-ion concentrations.
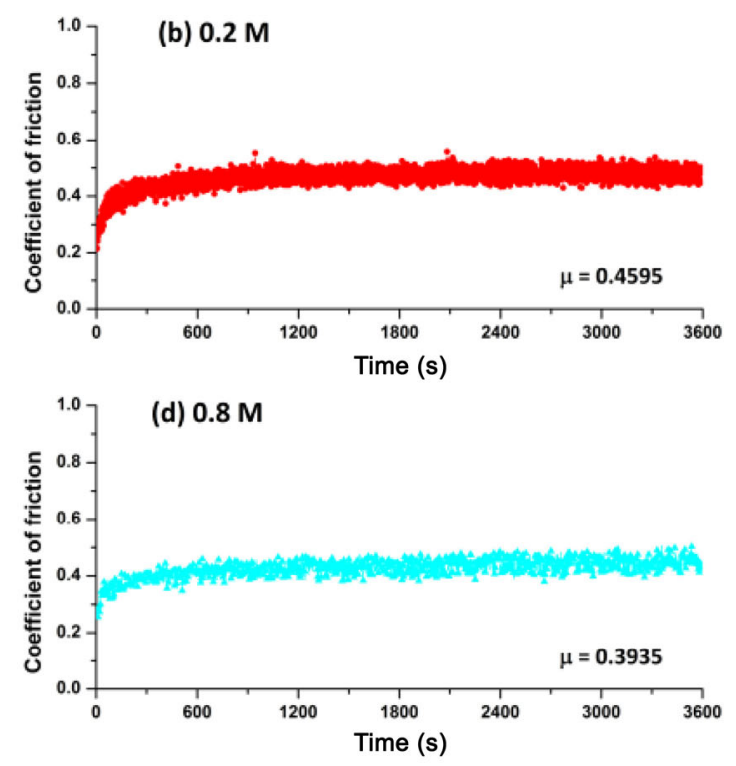

and the varying lubricating capability of solutions, SEM morphologies of the worn surface, subsurface, and wear debris after tribocorrosion tests in seawater with $0 \mathrm{M}$ and $1 \mathrm{M}$ halide concentrations were compared, and the results are shown in Figs. 6 and 7. Figures 6(a) and 6(b) show that a coarser worn surface was produced in halide-free solution, indicating that the wear of NAB was more severe in this solution. This was consistent with the COF and wear-rate results presented in Figs. 4 and 5. Moreover, grooves on wear scars were observed to be parallel to the sliding direction, which provided the evidence of abrasion during the rubbing process $[26,27]$. This abrasive wear was further confirmed by the ribbon-like wear debris formed throughout the course when hard asperities on the $\mathrm{Al}_{2} \mathrm{O}_{3}$ pin counterface continuously slid across the metal surface (as shown in Figs. 7(a) and 7(b)). Besides, the laminar tearing on wear scars generated after tribocorrosion in seawater with $1 \mathrm{M}$ halide concentration was milder compared with that observed in halide-free solution. At the same time, the examination

. 


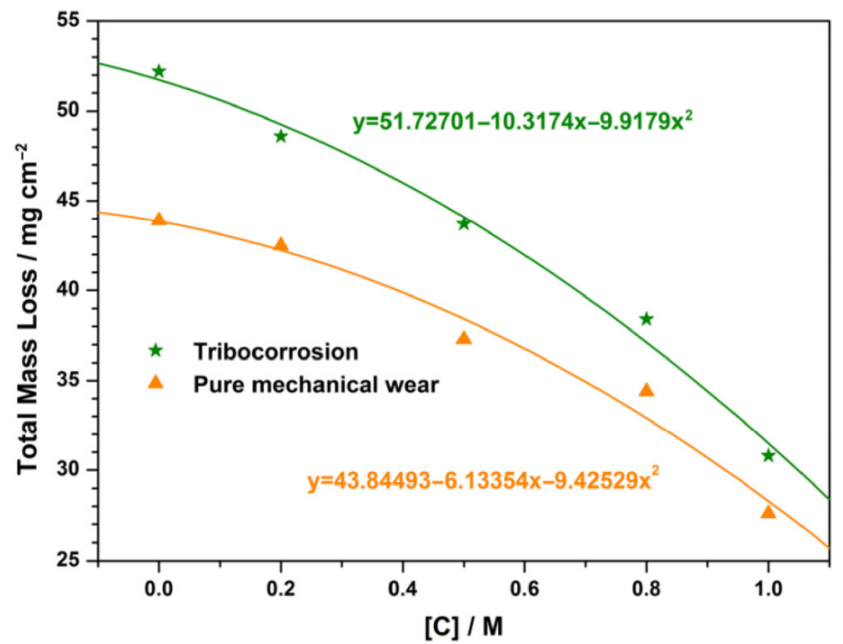

Fig. 5 Total mass-loss curves for NAB alloy in seawater with different halide-ion concentrations.
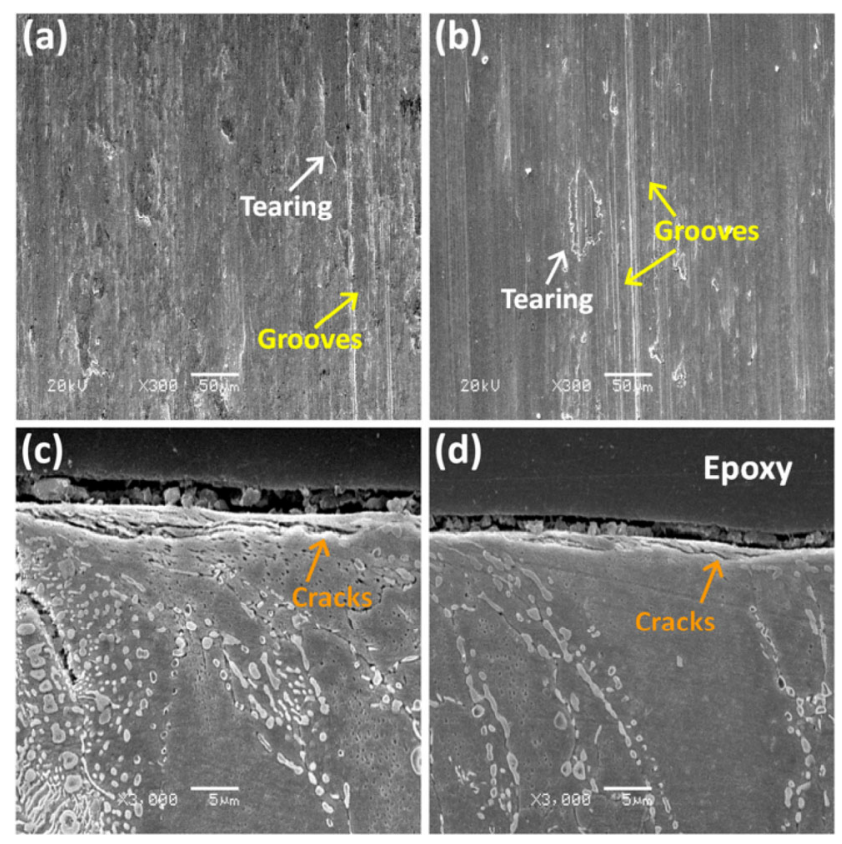

Fig. 6 SEM morphologies of worn surface and subsurface after tribocorrosion in seawater with ((a), (c)) $0 \mathrm{M}$ and ((b), (d)) $1.0 \mathrm{M}$ halide concentrations, respectively.

of wear debris revealed numerous sheets or flakes, which was a typical characteristic of delamination wear [28-30]. Clearly, the size of the wear debris in Fig. 7(b) was smaller than that presented in Fig. 7(a). Combined with the subsurface morphologies below the wear track of NAB (Figs. 6(c) and 6(d)), it demonstrated that delamination wear was also prevailing under these two kinds of lubricating conditions. In fact, some micro-cracks and plastic shear deformation,
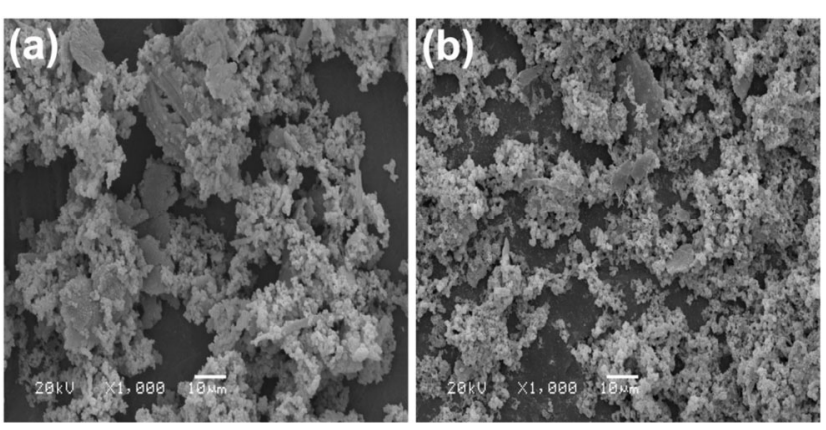

Fig. 7 SEM morphologies of wear debris after tribocorrosion in seawater with (a) $0 \mathrm{M}$ and (b) $1.0 \mathrm{M}$ halide concentrations, respectively.

which are typical features of delamination, can be detected underneath the metal surface. Further, the severity of plastic deformation and the thickness of the deformed region reduced with increasing halide concentration. As the halide concentration increased, the surface traction exerted by the harder $\mathrm{Al}_{2} \mathrm{O}_{3}$ pin on the softer $\mathrm{NAB}$ surface decreased owing to the better lubricity of the solution. In this case, there was a slight accumulation of plastic shear deformation, and a small number of cracks can be created at the subsurface, consequently yielding wear sheet particles with less thickness [31]. However, the loose corrosion products had a greater proportion in Fig. 7(b) compared with that in Fig. 7(a), indicating that heavier corrosion took place in high halide containing solutions. It is well known, that the tribological properties of a material are closely related to its microstructure. For NAB alloy, solute atoms such as iron, nickel, and aluminium can cluster and separate out from the matrix to form the dispersive $\kappa$ phases. The inclusion of $\beta^{\prime}$ and $\kappa$ phases would enhance the strength and hardness of NAB, preventing the alloy's surface from severe abrasive wear, and hence lowering the wear rate during tribocorrosion processes [32].

Figure 8 shows the transfer film that formed on alumina counterfaces after sliding in seawater with $0 \mathrm{M}$ and 1.0 $\mathrm{M}$ halide concentration. It can be observed that a discontinuous metallic transfer film was adhered on the alumina counterface, which is a typical result of adhesive wear (Figs. 8(a1) and 8(b1)). During the process of sliding, some junctions were formed between the asperities of two friction pairs, and then the asperities of the alumina pin may shear the NAB surface owing to their higher hardness. Hence, some 

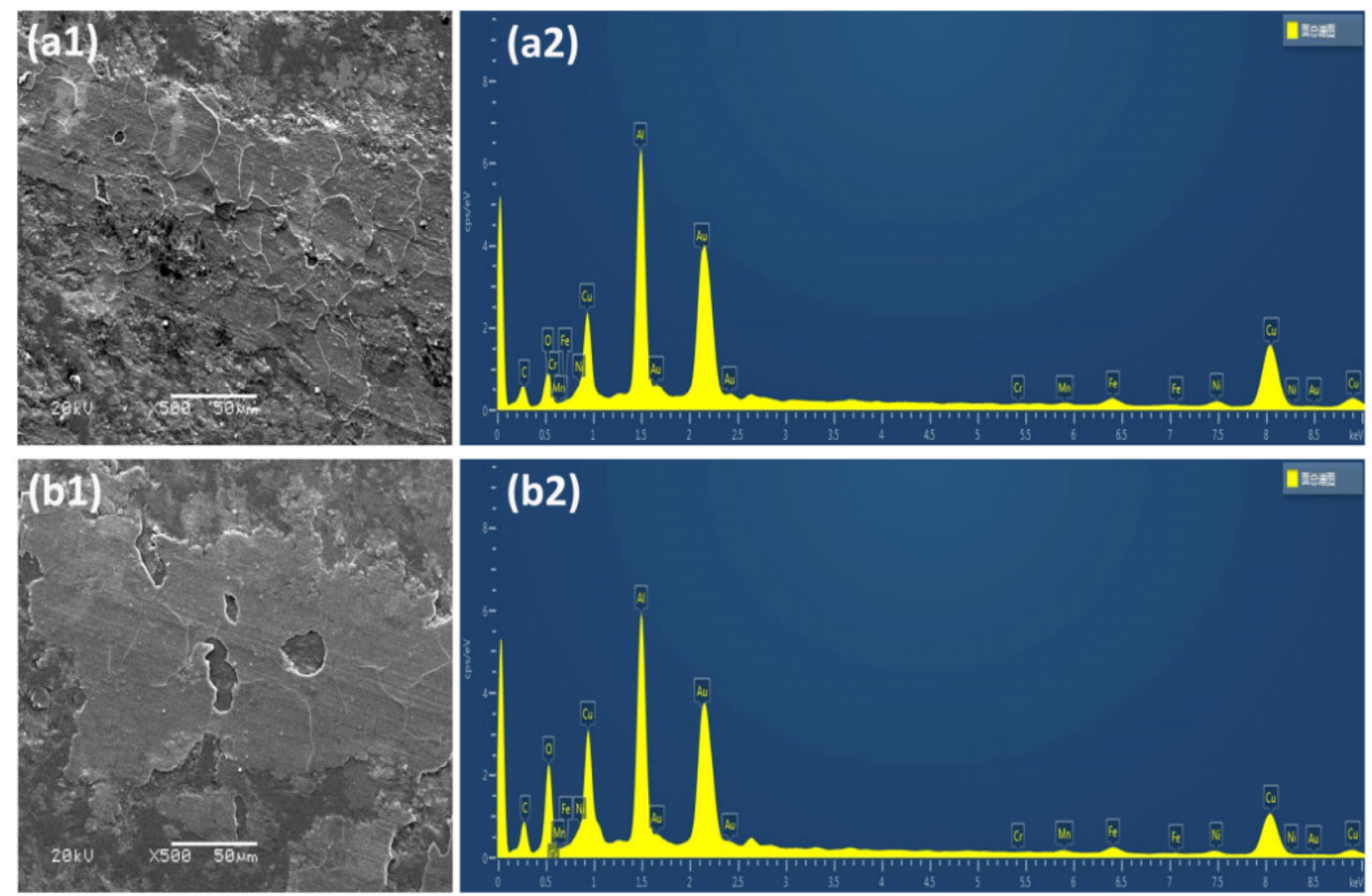

Fig. 8 SEM images and energy dispersive spectroscopy of counterfaces after sliding in seawater with ((a1), (a2)) 0 M and ((b1), (b2)) $1.0 \mathrm{M}$ halide concentrations.

materials were separated from NAB alloys and transferred to the alumina counterface. In addition, EDS results presented in Figs. 8(a2) and 8(b2) further validated the occurrence of adhesive failures between $\mathrm{NAB}$ alloys and the alumina pin.

\subsection{Wear-corrosion synergy}

The synergism between wear and corrosion is one of the main reasons for the damage of material from rubbing machine parts in aggressive media [33, 34]. Thus, it is imperative to quantify this synergistic effect in order to further understand the mechanism of tribocorrosion, establish a criterion to assess the tribocorrosion resistance of materials, and to take effective measures to control material degradation. According to the ASTM G119-09 standard, the wearcorrosion synergy can be estimated as:

$$
S=T-W_{0}-C_{0}
$$

where $S$ is the combined contribution owing to the synergistic effect, $T$ is the total material loss measured at the OCP, $W_{0}$ is the pure mechanical wear contribution measured at the cathodic protection potential, and $C_{0}$ is the pure corrosion contribution estimated from potentiodynamic polarization tests. To be consistent with the unit, all of the terms in Eq. (7) were given in $\mathrm{mm} / \mathrm{y}$. In addition, $S$ can also be attributed to the combined effect of wear-induced corrosion, $\Delta C_{w}$, and corrosion-induced wear, $\Delta W_{c}$, i.e.,

$$
S=\Delta C_{\mathrm{w}}+\Delta W_{\mathrm{c}}
$$

Besides, the degree of the synergy between wear and corrosion can be estimated by the following three dimensionless factors.

The total synergism factor:

$$
\frac{T}{T-S}
$$

The corrosion augmentation factor:

$$
\frac{C_{0}+\Delta C_{w}}{C_{0}}
$$

The wear augmentation factor:

$$
\frac{W_{0}+\Delta W_{\mathrm{c}}}{W_{0}}
$$

The synergistic contributions of the wear and 
corrosion for NAB alloy obtained by the procedure detailed above are shown in Fig. 9. It can be seen from Fig. 9(a) that all three factors were greater than one, indicating that wear and corrosion promoted each other and led to increased material loss. Besides, judging from Figs. 9(b)-9(d), it was clear that over the entire range of halide concentration, the total material loss of NAB alloy was dominated by wear, including pure mechanical wear and corrosion-induced wear. This was consistent with the criteria proposed by Stack et al. [35], which considered the ratio of the total corrosion rate $\left(C=C_{0}+\Delta C_{\mathrm{w}}\right)$ to the total wear rate $\left(W=W_{0}+\Delta W_{c}\right)$. For $C / W \leqslant 0.1$, wear is the primary contributor to material degradation; for $0.1<C / W \leqslant 10$, both wear and corrosion contribute significantly to material loss, and for $C / W>10$, corrosion is the dominant mechanism. In the present work, the values of $C / W$ varied from $6.31 \times 10^{-4}$ to $3.00 \times 10^{-3}$, which are well below 0.1 .

It was observed that in different tested electrolytes, the contribution of the corrosion component to the total material degradation for NAB may be negligible compared with that of the wear component. However, the acceleration of the corrosion rate was more obvious than the acceleration of the wear rate. Besides, the wear-induced corrosion rate displayed an upward trend with an increasing halide concentration in seawater (Fig. 9(b)). Based on the theory proposed by Mischler et al. [19], wear-induced corrosion is dependent on the passivation charge density and contact geometry, the latter of which is kept constant owing to the same mechanical condition during the sliding processes in this work. The passivation charge density is the anodic charge needed to passivate the bare metal, and thus depends on the electrochemical conditions of NAB in seawater with different halide concentrations. In seawater with a high halide concentration, the anodic dissolution of NAB was more serious, and resulted in a higher corrosion current density (Table 2), which eventually led to a larger $\Delta C_{\mathrm{w}}$.
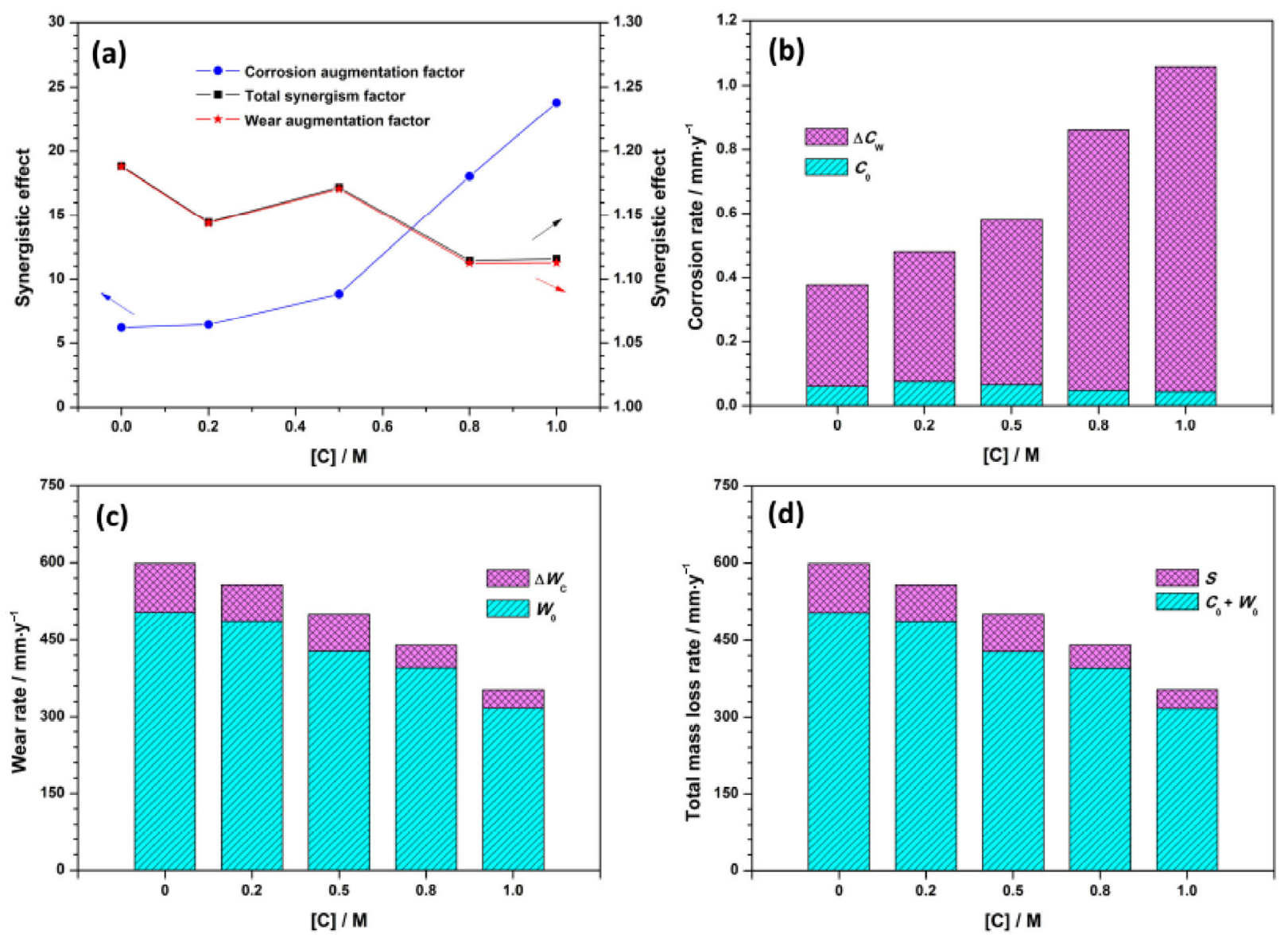

Fig. 9 Synergistic contributions of wear and corrosion of NAB alloy in seawater with different halide concentrations. 
However, the corrosion-induced wear rate accompanied by the pure wear rate decreased with an increasing halide concentration (Fig. 9(c)). It is well known that corrosion can promote the growth and propagation of microcracks on the contact surface as well as accelerates the wear rate. Nevertheless, seawater with a high halide concentration provides a good lubricating effect between the $\mathrm{NAB}$ and $\mathrm{Al}_{2} \mathrm{O}_{3}$ pin, and mitigated the impact of corrosion on wear. Therefore, with these two competing aspects working together, the downward trend of $\Delta W_{\mathrm{c}}$ was detected with an increasing halide concentration.

\section{Conclusions}

The present work was initiated with the aim of investigating the tribocorrosion failure mechanism of NAB alloy in seawater containing $0 \mathrm{M}, 0.2 \mathrm{M}$, $0.5 \mathrm{M}, 0.8 \mathrm{M}$, and $1.0 \mathrm{M}$ of halide ions. Electrochemical analyses revealed that the corrosion current density increased, and the corrosion potential shifted to a more negative value as the halide concentration of seawater increased. Moreover, the corrosion rate and corrosion susceptibility of $\mathrm{NAB}$ was found to increase owing to the destruction of the passive film by sliding, which led to the active dissolution of bare metal inside the wear track. In all of the cases studied, there was clearly a positive synergy between the wear and corrosion, which can be divided into two terms: wear-induced corrosion and corrosion-induced wear. The total material loss increased with increasing halide concentration, and above all, it was governed by the wear, including pure mechanical wear and corrosioninduced wear. In spite of the serious corrosivity of high halide concentration solution, its good lubricating ability alleviated the surface deterioration caused by tribological contact, and eventually resulted in minor material loss. Therefore, it can be concluded that the tribocorrosion behavior of NAB alloy in seawater is closely related to the halide-ion concentration that is present in it.

\section{Acknowledgements}

The work was financially supported by the National Natural Science Foundation of China (Grant No.
51405478) and CAS “Light of West China” Program.

Open Access: The articles published in this journal are distributed under the terms of the Creative Commons Attribution 4.0 International License (http://creativecommons.org/licenses/by/4.0/), which permits unrestricted use, distribution, and reproduction in any medium, provided you give appropriate credit to the original author(s) and the source, provide a link to the Creative Commons license, and indicate if changes were made.

\section{References}

[1] Antonijević M M, Milić S M, Šerbula S M, Bogdanović G D. The influence of chloride ions and benzotriazole on the corrosion behavior of $\mathrm{Cu} 37 \mathrm{Zn}$ brass in alkaline medium. Electrochim Acta 50(18): 3693-3701 (2005)

[2] Schüssler A, Exner H E. The corrosion of nickel-aluminium bronzes in seawater-II. The corrosion mechanism in the presence of sulphide pollution. Corros Sci 34(11): 1803-1811, 1813-1815 (1993)

[3] Bellantonio M. An integrated hard- and soft-ware triboelectrochemical test rig for tribocorrosion experiments. Friction 3(3): 256-258 (2015)

[4] Chen J, Wang J Z, Yan F Y, Zhang Q, Li Q A. Effect of applied potential on the tribocorrosion behaviors of Monel K500 alloy in artificial seawater. Tribol Int 81: 1-8 (2015)

[5] Chen J, Zhang Q, Li Q A, Fu S L, Wang J Z. Corrosion and tribocorrosion behaviors of AISI 316 stainless steel and Ti6A14V alloys in artificial seawater. Trans Nonferrous Met Soc China 24(4): 1022-1031 (2014)

[6] Zhang B B, Wang J Z, Zhang Y, Han G F, Yan F Y. Comparison of tribocorrosion behavior between 304 austenitic and 410 martensitic stainless steels in artificial seawater. RSC Adv 6(109): 107933-107941 (2016)

[7] Lenard D R, Bayley C J, Noren B A. Electrochemical monitoring of selective phase corrosion of nickel aluminum bronze in seawater. Corrosion 64(10): 764-772 (2008)

[8] Wang Y, Zhang L, Xiao J K, Chen W, Feng C F, Gan X P, Zhou K C. The tribo-corrosion behavior of $\mathrm{Cu}-9 \mathrm{wt} \% \mathrm{Ni}-6$ wt\% Sn alloy. Tribol Int 94: 260-268 (2016)

[9] Zhang R, Wang H F, Xing X G, Yuan Z, Yang S Y, Han Z J, Yuan G Z. Effects of Ni addition on tribocorrosion property of TiCu alloy. Tribol Int 107: 39-47 (2017)

[10] Wood R J K. Erosion-corrosion interactions and their effect on marine and offshore materials. Wear 261(9): 1012-1023 (2006) 
[11] Stemp M, Mischler S, Landolt D. The effect of mechanical and electrochemical parameters on the tribocorrosion rate of stainless steel in sulphuric acid. Wear 255(1-6): 466-475 (2003)

[12] Jørgensen F, Scheer W, Thomsen S, Sonnenborg T O, Hinsby K, Wiederhold H, Schamper C, Burschil T, Roth B, Kirsch R, et al. Transboundary geophysical mapping of geological elements and salinity distribution critical for the assessment of future sea water intrusion in response to sea level rise. Hydrol Earth Syst Sci 16(7): 1845-1862 (2012)

[13] Badawy W A, Ismail K M, Fathi A M. Effect of Ni content on the corrosion behavior of $\mathrm{Cu}-\mathrm{Ni}$ alloys in neutral chloride solutions. Electrochim Acta 50(18): 3603-3608 (2005)

[14] Ismail K, El-Egamy S S, Abdelfatah M. Effects of Zn and $\mathrm{Pb}$ as alloying elements on the electrochemical behaviour of brass in borate solutions. $J$ Appl Electrochem 31(6): 663-670 (2001)

[15] Zhang B B, Wang J Z, Zhang Y, Han G F, Yan F Y. Tribocorrosion behavior of 410SS in artificial seawater: Effect of applied potential. Mater Corros 68(3): 295-305 (2017)

[16] Al-Hashem A, Riad W. The role of microstructure of nickel-aluminium-bronze alloy on its cavitation corrosion behavior in natural seawater. Mater Charact 48(1): 37-41 (2002)

[17] Anantapong J, Uthaisangsuk V, Suranuntchai S, Manonukul A. Effect of hot working on microstructure evolution of ascast Nickel Aluminum Bronze alloy. Mater Des 60: 233-243 (2014)

[18] Lv Y T, Wang L Q, Han Y F, Xu X Y, Lu W J. Investigation of microstructure and mechanical properties of hot worked $\mathrm{NiAl}$ bronze alloy with different deformation degree. Mater Sci Eng A 643: 17-24 (2015)

[19] Mischler S, Muñoz A I. Wear of CoCrMo alloys used in metal-on-metal hip joints: A tribocorrosion appraisal. Wear 297(1-2): 1081-1094 (2013)

[20] Espallargas N, Johnsen R, Torres C, Muñoz A I. A new experimental technique for quantifying the galvanic coupling effects on stainless steel during tribocorrosion under equilibrium conditions. Wear 307(1-2): 190-197 (2013)

[21] Neodo S, Carugo D, Wharton J A, Stokes K R. Electrochemical behaviour of nickel-aluminium bronze in chloride media: Influence of $\mathrm{pH}$ and benzotriazole. $J$ Electroanal Chem 695: 38-46 (2013)

[22] Wharton J A, Stokes K R. The influence of nickel-aluminium bronze microstructure and crevice solution on the initiation of crevice corrosion. Electrochim Acta 53(5): 2463-2473 (2008)

[23] Duthil J P, Mankowski G, Giusti A. The synergetic effect of chloride and sulphate on pitting corrosion of copper. Corros Sci 38(10): 1839-1849 (1996)

[24] Kadhum A A H, Mohamad A B, Jaffar H D, Yan S S, Naama H J, Al-Tamimi A A, Al-Bayati R I, Al-Amiery A A. Corrosion of nickel-aluminum-bronze alloy in aerated $0.1 \mathrm{M}$ sodium chloride solutions under hydrodynamic condition. Int J Electrochem Sci 8: 4571-4582 (2013)

[25] Sun Y, Haruman E. Effect of electrochemical potential on tribocorrosion behavior of low temperature plasma carburized $316 \mathrm{~L}$ stainless steel in $1 \mathrm{M} \mathrm{H}_{2} \mathrm{SO}_{4}$ solution. Surf Coat Technol 205(17-18): 4280-4290 (2011)

[26] Cartigueyen S, Mahadevan K. Wear characteristics of copperbased surface-level microcomposites and nanocomposites prepared by friction stir processing. Friction 4(1): 39-49 (2016)

[27] Peng S G, Song R B, Sun T, Pei Z Z, Cai C H, Feng Y F, Tan Z D. Wear behavior and hardening mechanism of novel lightweight $\mathrm{Fe}-25.1 \mathrm{Mn}-6.6 \mathrm{Al}-1.3 \mathrm{C}$ steel under impact abrasion conditions. Tribol Lett 64: 13 (2016)

[28] Bortoleto E M, Prados E F, Seriacopi V, Fukumasu N K, da S Lima L G D B, Machado I F, Souza R M. Numerical modeling of adhesion and adhesive failure during unidirectional contact between metallic surfaces. Friction 4(3): 217-227 (2016)

[29] Chen H, Guo D, Xie G X, Pan G S. Mechanical model of nanoparticles for material removal in chemical mechanical polishing process. Friction 4(2): 153-164 (2016)

[30] Suh N P. An overview of the delamination theory of wear. Wear 44(1): 1-16 (1977)

[31] Saka N, Eleiche A M, Suh N P. Wear of metals at high sliding speeds. Wear 44(1): 109-125 (1977)

[32] Li W S, Wang Z P, Lu Y, Jin Y H, Yuan L H, Wang F. Mechanical and tribological properties of a novel aluminum bronze material for drawing dies. Wear 261(2): 155-163 (2006)

[33] Cheng J, Wang T Q, Chai Z M, Lu X C. Tribocorrosion study of copper during chemical mechanical polishing in potassium periodate-based slurry. Tribol Lett 58(1): 8 (2015)

[34] Motamen Salehi F, Khaemba D N, Morina A, Neville A. Corrosive-abrasive wear induced by soot in boundary lubrication regime. Tribol Lett 63(2): 19 (2016)

[35] Hodge C, Stack M M. Tribo-corrosion mechanisms of stainless steel in soft drinks. Wear 270(1-2): 104-114 (2010) 


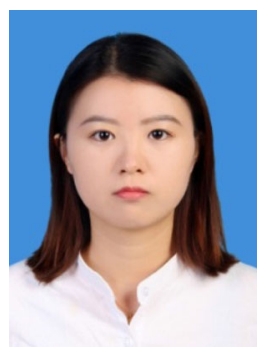

Beibei ZHANG. She received her bachelor degree in 2014 from Henan University of Science and Technology. After then, she was a Ph.D

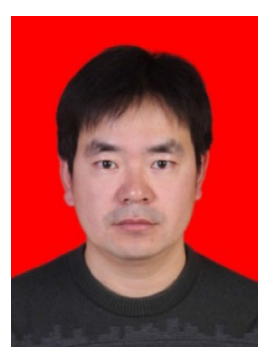

Jianzhang WANG. He received his Ph.D degree in materialogy from Lanzhou Institute of Chemical Physics, Chinese Academy of Sciences in 2010. He joined the State Key

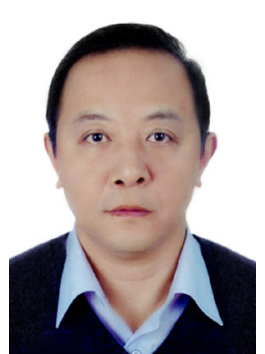

Fengyuan YAN. He received his M.S. and Ph.D degrees in tribology and physical chemistry from Lanzhou Institute of Chemical Physics, Chinese Academy of Sciences, respectively in 1991 and 1997. He joined the State Key Laboratory of student in the State Key Laboratory of Solid Lubrication at Lanzhou Institute of Chemical Physics, Chinese Academy of Sciences. Her research interests include the metal corrosion and protection.

Laboratory of Solid Lubrication at Lanzhou Institute of Chemical Physics from 2010. His current position is an associate professor. His research areas cover the ocean tribology and functional composites.

Solid Lubrication at Lanzhou Institute of Chemical Physics from 1999. His current position is a professor and the deputy director of the laboratory. His research areas cover the ocean tribology, tribological mechanism of composites, functional materials, and tribological testing technique. 